\title{
ROCK ARMOR DAMAGE IN DEPTH-LIMITED BREAKING WAVE CONDITIONS
}

\author{
Josep R. Medina ${ }^{1}$, María P. Herrera² ${ }^{\text {and M. Esther Gómez-Martín }}{ }^{3}$
}

\begin{abstract}
The armor layer of a mound breakwaters is usually designed with a formula derived from physical tests in nonbreaking wave conditions; however, most rubble mound breakwaters are placed in the wave breaking zone where the highest waves break before reaching the structure. The hydraulic stability formulas developed for rock-armored breakwaters in non-breaking conditions are not completely valid to characterize the hydraulic stability of these structures under depth-limited wave attack. In this study, five series of 2D physical tests were carried out on a bottom slope $\mathrm{m}=1 / 50$ to analyze the hydraulic stability of double-layer rock armored breakwaters in depth-limited breaking wave conditions. Measurements taken by 12 wave gauges placed along the wave flume were compared with estimations of $\mathrm{H}_{m 0}, \mathrm{H}_{2}$ and $\mathrm{H}_{1 / 10}$ obtained from numerical model SwanOne. The significant wave height, $\mathrm{H}_{\mathrm{m} 0}$, estimated or measured at a distance $3 \mathrm{~h}_{\mathrm{s}}$ from the toe of the structure was the best characteristic wave to relate armor damage with stability number. The six-power relationship between dimensionless armor damage and stability number, found in this study, explained more than $94 \%$ of the variance in the damage observations. This relationship is valid for conventional non-overtopping double-layer rock-armored breakwaters on bottom slope m=1/50 and depth-limited breaking wave conditions.
\end{abstract}

Keywords: rock armor; rubble mound breakwater; hydraulic stability; shallow water; breaking wave conditions

\section{INTRODUCTION}

The armor layer of a mound breakwater is usually designed with a formula derived from physical tests in non-breaking wave conditions; however, most rubble mound breakwaters are placed in the wave breaking zone where the highest waves break before reaching the structure.

Since the pioneering work of Iribarren (1938), different formulas have been published to characterize the hydraulic stability of rock armors, such as those provided by Hudson (1959), Van der Meer (1988), Van Gent et al. (2003) and other authors. Most of these formulas are based on 2D physical tests with models in non-breaking wave conditions. Significant wave height, $\mathrm{H}_{\mathrm{m} 0}$, at the toe of the structure and wave height with a $2 \%$ exceedance probability, $\mathrm{H}_{2 \%}$, are usually considered to describe the incident wave characteristics in non-breaking wave conditions. $\mathrm{H}_{2} \%$ is strongly correlated to $\mathrm{H}_{\mathrm{m} 0}$ in deep water when wave heights are Rayleigh-distributed, but this is not the case in depthlimited breaking wave conditions (see Battjes and Groenendijk, 2000).

The formula given by Hudson (1959) and popularized later by USACE $(1975,1984)$ has been generally used for decades to design rubble mound breakwaters around the world; Eq. 1 is equivalent to the Hudson formula which was based on results from 2D small-scale tests in non-breaking conditions using regular waves. $\mathrm{K}_{\mathrm{D}}$ is the stability coefficient which depends on the type of the armor unit, number of layers, breakwater section (trunk or roundhead), armor slope ( $\cot \alpha$ ), and an implicit safety factor for design (see Medina and Gómez-Martín, 2012). Eq. 1 does not consider the wave steepness and the duration of the wave storm, the permeability of core and filter layers, grade of stones and other variables or parameters affecting the hydraulic stability of the armor layer. Nevertheless, Eq. 1 is still widely used by practitioners for preliminary designs of mound breakwaters.

$$
N_{s}=\frac{H}{\Delta D_{n 50}}=\left(K_{D} \cot \alpha\right)^{1 / 3}
$$

in which $\mathrm{N}_{\mathrm{s}}$ is the stability number, $\mathrm{D}_{\mathrm{n} 50}=\left(\mathrm{W}_{50} / \gamma_{\mathrm{r}}\right)^{1 / 3}$ is the nominal diameter of the armor rocks, $\mathrm{W}_{50}$ is the median rock weight, $\Delta=\left(\gamma_{\mathrm{r}}-\gamma_{\mathrm{w}}\right) / \gamma_{\mathrm{w}}$ is the relative submerged specific weight, $\gamma_{\mathrm{r}}$ is the specific weight of the rocks, $\gamma_{\mathrm{w}}$ is the specific weight of the water, $\mathrm{H}$ is a characteristic wave height, and $\alpha$ is the structure slope angle. USACE (1975) and USACE (1984) proposed using the significant wave height $\left(\mathrm{H}_{\mathrm{s}}\right)$ and the average of the highest $1 / 10$ of waves $\left(\mathrm{H}_{1 / 10}\right)$, respectively, as the characteristic wave height for design; in non-breaking conditions, wave heights are approximately Rayleigh distributed with $\mathrm{H}_{1 / 10} \approx 1.27 \mathrm{H}_{\mathrm{s}}$. When using $\mathrm{H}=\mathrm{H}_{\mathrm{s}}$ (USACE, 1975), the stability coefficient for rough angular rocks is $\mathrm{K}_{\mathrm{D}}=3.5$ for breaking conditions and $\mathrm{K}_{\mathrm{D}}=4.0$ for non-breaking conditions. When using $\mathrm{H}=\mathrm{H}_{1 / 10} \approx 1.27 \mathrm{H}_{\mathrm{s}}$ (USACE, 1984), the stability coefficient for rough angular rocks is $\mathrm{K}_{\mathrm{D}}=2.0$ for breaking conditions and $\mathrm{K}_{\mathrm{D}}=4.0$ for non-breaking conditions.

\footnotetext{
${ }^{1}$ Institute of Transport and Territory, Univ. Politècnica de València, Camino de Vera s/n, 46022 Valencia, Spain

2 PROES Consultores S.A., Calle General Yagüe 39, 28020 Madrid, Spain

${ }^{3}$ Institute of Transport and Territory, Univ. Politècnica de València, Camino de Vera s/n, 46022 Valencia, Spain
} 


\section{Depth-limited breaking wave conditions}

USACE $(1975,1984)$ provided a method to estimate the design wave height $\left(\mathrm{H}_{\mathrm{b}}\right)$ for regular waves in depth-limited breaking wave conditions, depending on the deep-water wave height, wave period and the bottom slope; however, no specifications were given about which characteristic wave height $\mathrm{H}$ should be used in Eq. 1 when dealing with irregular waves in depth-limited breaking wave conditions. It is obvious that USACE (1984) introduced an additional safety factor for designing rock-armored breakwaters when compared to USACE (1975) in breaking and non-breaking conditions.

Van der Meer (1988) analyzed more than three hundred experimental tests to propose his wellknown 10-parameter and 4-variable formula (see Eq. 2) to estimate the armor damage in a conventional rubble mound breakwater as function of the stability number.

$$
N_{s}=\frac{H_{S}}{\Delta D_{n 50}}=S^{1 / 5} \cdot\left(\max \left[f_{1}(I r, P, N) ; f_{2}(\operatorname{Ir}, P, N, \cot \alpha)\right]\right)
$$

in which $\mathrm{S}$ is the dimensionless armor damage, Ir is Iribarren's number or surf similarity parameter, $\mathrm{P}$ is the notional permeability, $\mathrm{N}$ is the number of waves in the run, and $\mathrm{f}_{1}$ and $\mathrm{f}_{2}$ are 3 -variable and 4variable functions, respectively, with a total of 10 parameters calibrated from the experimental observations. The 5-power relationship between dimensionless armor damage and stability number explicitly described by Van der Meer (1988) was also implicitly proposed (see Medina et al., 1994) by USACE $(1975,1984)$ and explicitly proposed by other authors such as Melby and Kobayashi (1998) and Van Gent et al. (2003). Nevertheless, only 5\% of the tests analyzed by Van der Meer (1988) corresponded to armors in breaking wave conditions (permeable core and $\mathrm{m}=1 / 30$ bottom slope); when Van der Meer formulas were used for breakwaters in breaking wave conditions, $\mathrm{H}_{2 \%} / 1.4$ was proposed to be used instead of the significant wave height, $H_{s}$. The relationship $H_{2} \% / 1.4=H_{s}$ is valid if wave heights are Rayleigh distributed (non-breaking wave conditions) but this is a conservative criterion if the highest waves break before reaching the structure (breaking wave conditions).

Some intuitive or empirical modifications have been proposed to take into account the depthinduced breaking wave conditions; however, few physical tests in breaking wave conditions have been reported in the literature. Furthermore, analyzing single-layer interlocking armors, GómezMartín at al. (2018) pointed out contradictory recommendations found in the literature; CLI (2018) recommended using lower values of $\mathrm{K}_{\mathrm{D}}$ for breaking wave conditions compared to non-breaking conditions, and $\mathrm{Xbloc}^{\circledR}$ (2014) higher values of $\mathrm{K}_{\mathrm{D}}$ for breaking wave conditions.

According to the available research, it is clear that a steeper bottom slope reduces the hydraulic stability of the armor layer, yet it is not clear if the breaking wave condition increases or decreases the hydraulic stability of the armor layer. Melby and Kobayashi (1998) and Van Gent et al. (2003) proposed formulas for double-layer rock armors based on 2D hydraulic stability tests in breaking wave conditions $\left(0.64<\mathrm{H}_{\mathrm{s}} / \mathrm{h}_{\mathrm{s}}<1.11\right.$ and $0.15<\mathrm{H}_{\mathrm{s}} / \mathrm{h}_{\mathrm{s}}<0.78$, respectively), where $\mathrm{h}_{\mathrm{s}}$ is the water depth at the toe of the structure. Different bottom slopes $(m=1 / 20,1 / 30$ and $1 / 100)$ and armor slopes $(\cot \alpha=$ $\mathrm{H} / \mathrm{V}=2$ and 4) were tested; however, the measurement of incident $\mathrm{H}_{\mathrm{s}}$ at the toe of the structure in breaking wave conditions is much more difficult than that of incident $\mathrm{H}_{\mathrm{s}}$ in non-breaking wave conditions (see Herrera et al., 2017). Furthermore, there are few tests in breaking-wave conditions reported in the literature, and it is not clear what methodology must be applied to correctly measure the incident significant wave height at the toe of the structure when waves are breaking.

Herrera et al. (2017) carried out 2D physical tests to study the hydraulic stability of double-layer rock armors in breaking wave conditions $\left(0.20<\mathrm{H}_{\mathrm{s}} / \mathrm{h}_{\mathrm{s}}<0.90\right)$. Different methods were compared to estimate the incident wave characteristics, including wave measurements with and without structure at different locations along the wave flume with the numerical model SwanOne. The spectral significant wave height $\left(\mathrm{H}_{\mathrm{s}}\right)$ estimated by SwanOne at a seaward distance of $3 \mathrm{~h}_{\mathrm{s}}$ from the breakwater toe, was found to be the best for most applications, where $h_{s}$ is the water depth at the toe. Herrera et al. (2017) observed a 6-power relationship between the equivalent dimensionless armor damage $\left(\mathrm{S}_{\mathrm{e}}\right)$ and the stability number for armor slope $\cot \alpha=H / V=1.5$, bottom slope $m=1 / 50$ and permeable core; Eq. 3 is equivalent to the formula given by Herrera et al. (2017). In this case, the measured armor damage $\mathrm{S}$ was accumulative with increasing values of $\mathrm{H}_{\mathrm{s}}$ in runs of 1000 waves from no damage to Initiation of Destruction (IDe), rusn of waves with the same wave steepness and water depth at the toe of the structure; neither Ir nor $h_{s}$ were significant explanatory variables for the observed armor damage.

$$
N_{S}=\frac{H_{S}}{\Delta D_{n 50}}=1.57 \cdot S^{1 / 6}
$$


This study focuses the appropriate methodologies for 2D small-scale tests to analyze the hydraulic stability of mound breakwaters in breaking wave conditions. After the introduction, the experimental methodology used by Herrera et al. (2017) is discussed first; later, the analysis of results is carried out and conclusions are given.

\section{EXPERIMENTAL SET-UP}

Herrera et al. (2017) carried out 57 physical tests in the wave flume (30x1.2x1.2 meters) of the Laboratory of Ports and Coasts at the Universitat Politècnica de València (LPC-UPV). Series of runs of waves with JONSWAP $(\gamma=3.3)$ spectra were generated with constant water depth, $\mathrm{h}_{\mathrm{s}}$, and constant Iribarren number, $\operatorname{Ir}_{\mathrm{p}}=\tan \alpha /\left(2 \pi \mathrm{H}_{\mathrm{s}} /\left[\mathrm{gT}_{\mathrm{p}}{ }^{2}\right]\right)^{1 / 2}$, where $\mathrm{T}_{\mathrm{p}}$ is the peak period. Spectral significant wave height at the wave generating zone, $\mathrm{H}_{\mathrm{s}}=4\left(\mathrm{~m}_{0}\right)^{1 / 2}$, was increased progressively within each series of tests. Thirteen wave gauges were placed along the wave flume (see Fig. 1) and the model was placed on a mild bottom slope, $m=1 / 50$. Wave gauges $G 1$ to $G 4$ were placed in relatively deep water, whereas incident and reflected waves were separated uing the LASA-V method developed by Figueres and Medina (2004). Wave gauges G5 to G12 were placed along the sloping $m=1 / 50$ foreshore, where wave heights are depth-limited. Finally, G13 was placed behind the structure to measure the mean water level during the tests.

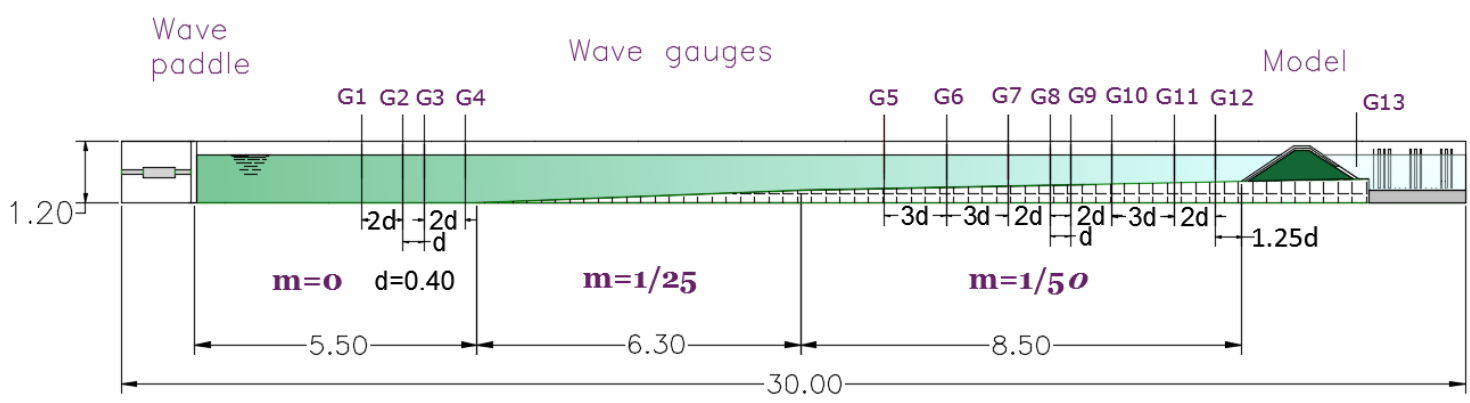

Figure 1. Longitudinal cross-section of the LPC_UPV wave flume (dimensions in meter).

An effective passive wave absorption system was placed at the end of the wave flume, and several tests were repeated without structure to measure the total waves as the incident waves in breaking wave conditions. The wave-maker used an active wave absorption system (AWACS) to avoid multi-reflections during the tests. SwanOne software was used to simulate the waves breaking along the wave flume and to compare characteristic wave heights $\left(\mathrm{H}_{\mathrm{s}}, \mathrm{H}_{1 / 10}\right.$ and $\left.\mathrm{H}_{2 \%}\right)$, measured at wave gauges G5 to G12 to estimations given by SwanOne (see Verhagen et al., 2008). Table 1 shows the test characteristics with incident waves measured at the wave generation zone.

Table 1. Test matrix.

\begin{tabular}{cccccccc}
\hline Series & $h_{s}(\mathrm{~cm})$ & $I r_{p}$ & $S_{0 p}$ & $H_{s}(\mathrm{~cm})$ & $T_{p}(\mathrm{~s})$ & \# wave runs & \# waves, $N$ \\
\hline 1 & 20 & 3.0 & 0.049 & $8.0-18.0$ & $1.02-1.53$ & 11 & 1000 \\
2 & 20 & 5.0 & 0.018 & $8.0-15.0$ & $1.70-2.32$ & 8 & 1000 \\
3 & 30 & 3.0 & 0.049 & $8.0-17.0$ & $1.02-1.48$ & 10 & 1000 \\
4 & 30 & 5.0 & 0.018 & $8.0-14.0$ & $1.70-2.25$ & 7 & 1000 \\
5 & 40 & 3.0 & 0.049 & $8.0-16.0$ & $1.02-1.44$ & 9 & 1000 \\
\hline
\end{tabular}

Five series of tests were conducted; these series were characterized by a constant water depth at the toe of the structure, $h_{s}(\mathrm{~cm})=20,30$ or 40 , and a constant Iribarren number, $\mathrm{Ir}_{\mathrm{p}}=3.0$ or 5.0. Runs of $\mathrm{N}=1000$ irregular waves were generated for each test in a given series; incident significant wave height, $H_{s}=4\left(m_{0}\right)^{1 / 2}$, in the wave generation zone (wave gauges $G 1$ to $G 4$ ) characterize each 
test within the series $\left(\mathrm{H}_{\mathrm{s}} / \mathrm{h}_{\mathrm{s}}<0.29\right)$. Significant wave height at the wave generating zone was increased progressively from no-damage $(\mathrm{Hs}(\mathrm{cm})=8.0)$ to Initiation of Destruction (IDe), wave breaking at the wave generation zone or significant overtopping. After each test, the accumulated equivalent dimensionless armor damage $\left(\mathrm{S}_{\mathrm{e}}\right)$ was measured using the Virtual Net method described by Gómez-Martín and Medina (2014). The dimensionless armor damage $S$ is equivalent to $\mathrm{S}_{\mathrm{e}}$ when heterogeneous packing is negligible. In this study, the armor damage $S_{e}$ corresponding to a test characterized by $\mathrm{H}_{\mathrm{sk}}$ corresponded to the accumulated armor damage caused by the attack of all the runs of one thousand waves in the same series with $\mathrm{Hs} \leq \mathrm{H}_{\text {sk. }}$.

Fig. 2 illustrates the breakwater model tested in this study; as only one armor slope $(\cot \alpha=\mathrm{H} / \mathrm{V}=1.5)$ was tested, the wave steepness of the test series was related to the Iribarren number, $\mathrm{s}_{0 \mathrm{p}}=\left(1.5 \mathrm{Ir}_{\mathrm{p}}\right)^{-2}$. The model corresponds to a non-overtopping double-layer rock armored breakwater with a nominal diameter $D_{n 50}[\mathrm{~cm}]=3.18$ and mass density $\rho_{r}\left(\mathrm{~g} / \mathrm{cm}^{3}\right)=2.677$. The rock armor was placed on a filter layer and permeable core, the filter layer with $D_{n 50}(\mathrm{~cm})=1.78$ and $\mathrm{D}_{\mathrm{n} 85} / \mathrm{D}_{\mathrm{n} 15}=1.35$ and the core with $\mathrm{D}_{\mathrm{n} 50}(\mathrm{~cm})=0.68$ and $\mathrm{D}_{\mathrm{n} 85} / \mathrm{D}_{\mathrm{n} 15}=1.64$.

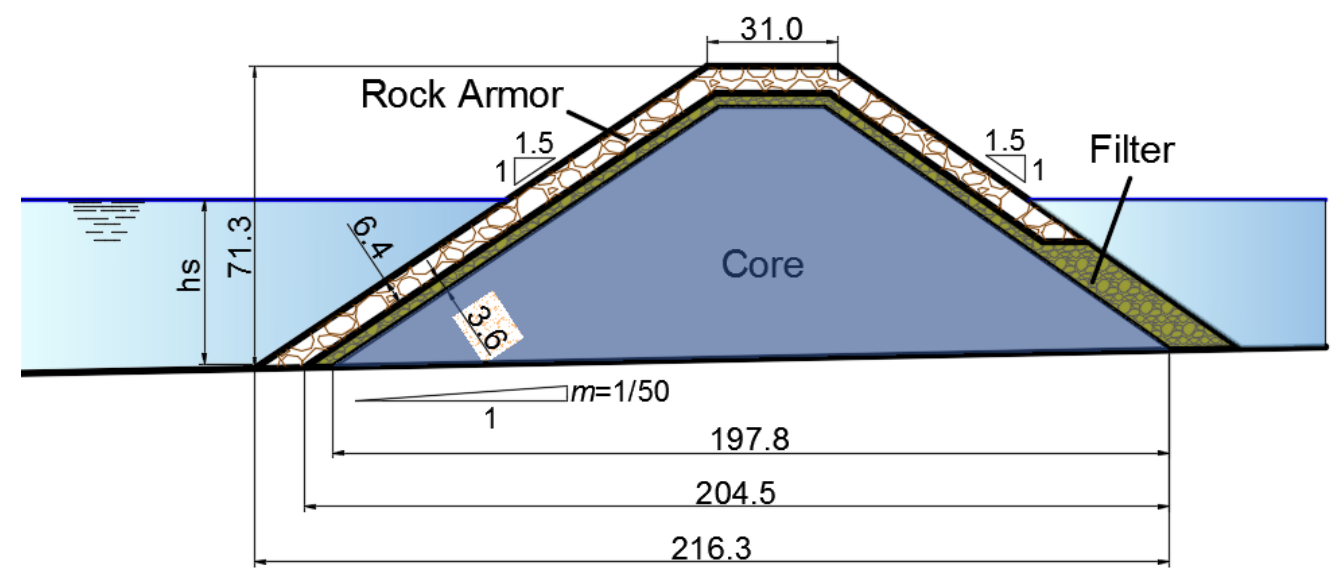

Figure 2. Cross-section of the model (dimensions in centimeters).

\section{ANALYSIS OF RESULTS}

Wave gauge measurements were taken without the structure and SwanOne software was used to estimate the depth-limited incident breaking waves based on incident waves estimated at the wave generation zone (G1 to G4) using the method developed by Figueres and Medina (2004). Fig. 3 compares the incident wave height characteristics $\left(\mathrm{H}_{\mathrm{m} 0}\right.$ and $\left.\mathrm{H}_{2 \%}\right)$ estimated with SwanOne software and the measurements taken without structure; the agreement was excellent for the significant wave height, $\mathrm{H}=\mathrm{H}_{\mathrm{m} 0}$. 


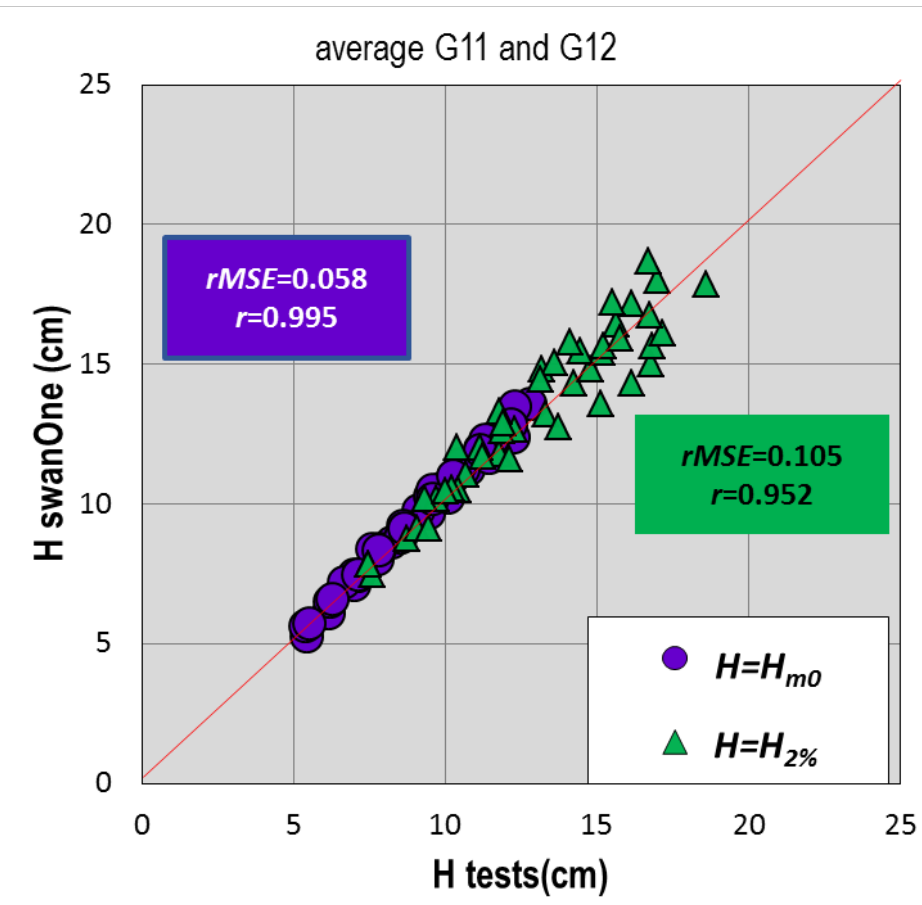

Figure 3. Comparison of average measured characteristic wave height at $G 11$ and $G 12\left(H_{m 0}\right.$ and $\left.H_{2 \%}\right)$, without the structure and estimations by SwanOne with the structure.

The correlation coefficient, $(0 \leq \mathrm{r} \leq 1)$ and the relative Mean Squared Error (rMSE) given by Eq. 4, which estimate the proportion of variance not explained by the model $(0 \leq \mathrm{rMSE} \leq 1)$, were used to measure the goodness of fit. In this case, the significant wave height $\mathrm{H}_{\mathrm{m} 0}$ estimated by SwanOne explained $94.2 \%$ of the variance in the measured $\mathrm{H}_{\mathrm{m} 0}$ without the structure (rMSE=5.8\% and $\mathrm{r}=99.5 \%$ ); the agreement between measures and estimated $\mathrm{H}_{\mathrm{m} 0}$ was excellent, the agreement was not so good between measured and estimated $\mathrm{H}_{2} \%$.

$$
r M S E=\frac{M S E}{\operatorname{Var}}=\frac{\frac{1}{N_{O}} \sum_{n=1}^{N_{O}}\left(e_{n}-o_{n}\right)^{2}}{\frac{1}{N_{O}} \sum_{n=1}^{N_{O}}\left(o_{n}-\bar{o}\right)^{2}}
$$

where MSE is the mean squared error, Var is the variance of the observations, $\mathrm{N}_{\mathrm{o}}$ is the number of observations, $e_{n}$ is the $n^{\text {th }}$ estimated value, $o_{n}$ is the $n^{\text {th }}$ observed value, and $\bar{o}$ is the average of the observed values.

When the model was tested, incident and reflected waves were separated in the wave generation zone, and SwanOne software was used to estimate $\mathrm{H}_{\mathrm{m} 0}$ and $\mathrm{H}_{2} \%$ along the wave flume from the incident waves at the wave generation zone. To identify the most relevant hydraulic and structural variables, stability number, $\mathrm{N}_{\mathrm{s}}$, wave steepness $\mathrm{s}_{\mathrm{m}}$, and water depth at the toe, $\mathrm{h}_{\mathrm{s}}$, were considered to estimate dimensionless armor damage according to

$$
S=k_{1}\left(\frac{H}{\Delta D_{n 50}}\right)^{k_{2}}\left(s_{m}\right)^{k_{3}}\left(h_{s}\right)^{k_{4}}
$$

where $\mathrm{S}$ is the dimensionless armor damage, $\mathrm{H}$ is the characteristic wave height $\left(\mathrm{H}_{\mathrm{m} 0}\right.$ or $\left.\mathrm{H}_{2 \%}\right), \Delta$ is the relative submerged mass density, Dn50 is the nominal diameter, $\mathrm{s}_{\mathrm{m}}=\mathrm{H}_{\mathrm{m} 0} / \mathrm{L}_{\mathrm{m}}$ is the wave steepness, $\mathrm{h}_{\mathrm{s}}$ is the water depth at the toe and $\mathrm{k}_{1}$ to $\mathrm{k}_{4}$ are parameters to be estimated. However, a t-student test (5\% level of significance) discarded wave steepness and water depth at the toe; only the stability number was a significant input and only two parameters should be estimated as shown in Eq. 6. Neither the Iribarren number nor $h_{s}$ were significant explanatory variables for the observed armor damage. In breaking wave conditions, both water depth at the toe and wave steepness affect the stability of the armor layer, but the observations of this study indicate that this influence is well characterized by the significant wave height $\left(\mathrm{H}_{\mathrm{m} 0}\right)$ measured or estimated (SwanOne) in front of the structure. 
In this study, significant wave height $\left(\mathrm{H}_{\mathrm{m} 0}\right)$ was a better wave height descriptor than $\mathrm{H}_{2 \%}$ to estimate rock armor damage in depth-limited breaking wave conditions. Fig. 4 compares damage observations and predictions given by Eq. 6.

$$
S=k_{1}\left(\frac{H}{\Delta D_{n 50}}\right)^{k_{2}}
$$

where $\mathrm{k}_{1}$ and $\mathrm{k}_{2}$ were calibrated using SwanOne estimations for $\mathrm{H}=\mathrm{H}_{\mathrm{m} 0}$ and $\mathrm{H}=\mathrm{H}_{2} \% ; \mathrm{H}_{\mathrm{m} 0}$ and $\mathrm{H}_{2} \%$ were estimated at five points in front of the structure (distances to the toe: $0, h_{s}, 2 h_{s}, 3 h_{s}$ and $4 h_{s}$ ). The best results (minimum rMSE) were found at a distance of $3 \mathrm{~h}_{\mathrm{s}}$ from the toe of the structure. The results were $\mathrm{k}_{1}=0.066$ and $\mathrm{k}_{2}=6.0$ for $\mathrm{H}=\mathrm{H}_{\mathrm{m} 0}$, and $\mathrm{k}_{1}=0.010$ and $\mathrm{k}_{2}=6.0$ for $\mathrm{H}=\mathrm{H}_{2} \%$. Eq. 3 is equivalent to Eq. 7a when $\mathrm{H}=\mathrm{H}_{\mathrm{m} 0}=\mathrm{H}_{\mathrm{s}}$; in this case, the measured armor damage $\mathrm{S}$ was accumulative with increasing values of $\mathrm{H}_{\mathrm{m} 0}$ in runs of 1000 waves from no damage to Initiation of Destruction (IDe). The runs of waves have the same wave steepness and water depth at the toe of the structure. The $90 \%$ confidence interval of Ns given by Eq. 7a is found using Eqs. 7b and 7c

$$
\begin{aligned}
& N_{S}(50 \%)=\frac{H_{S}}{\Delta D_{n 50}}=1.57 \cdot S^{1 / 6} \\
& N_{S}(95 \%)=N_{S}(50 \%)+\frac{0.33}{N_{S}^{2}(50 \%)} \\
& N_{S}(5 \%)=N_{S}(50 \%)-\frac{0.33}{N_{S}^{2}(50 \%)}
\end{aligned}
$$

where $\mathrm{N}_{\mathrm{s}}(\mathrm{m} \%)$ is the $\mathrm{m} \%$ percentile of the stability number $\mathrm{N}_{\mathrm{s}}$ and $\mathrm{S}$ is dimensionless armor damage. In this case, the dimensionless armor damage $(\mathrm{S})$ is equal to the equivalent dimensionless armor damage because heterogeneous packing was negligible.

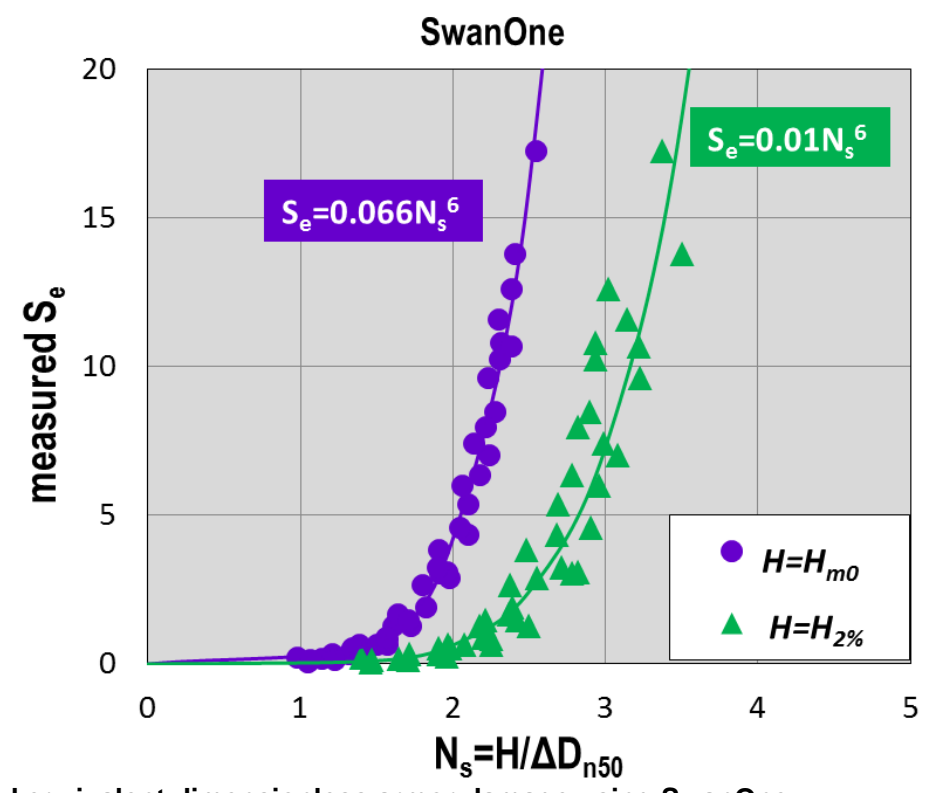

Figure 4. Measured equivalent dimensionless armor damage using SwanOne.

Considering the methodology given by Medina et al. (1994) and Herrera et al. (2017), Fig. 5 shows the armor damage function given by USACE (1975) based on tests using regular waves. Assuming $\mathrm{H}=\mathrm{H}_{\mathrm{m} 0}$, the data provided by USACE (1975) lead to Eq. 8 which has some resemblance to Eq. 7a obtained in this study.

$$
N_{S}=\frac{H}{\Delta D_{n 50}}=1.62 \cdot S^{1 / 5}
$$


where Ns is the stability number, $\mathrm{H}$ is the regular wave height and $\mathrm{S}$ is the dimensionless armor damage ( $\mathrm{S}=\mathrm{S}_{\mathrm{e}}$ in this case). On the contrary, assuming $\mathrm{H}=\mathrm{H}_{1 / 10}$, the data provided by USACE (1984) lead to a completely different result.

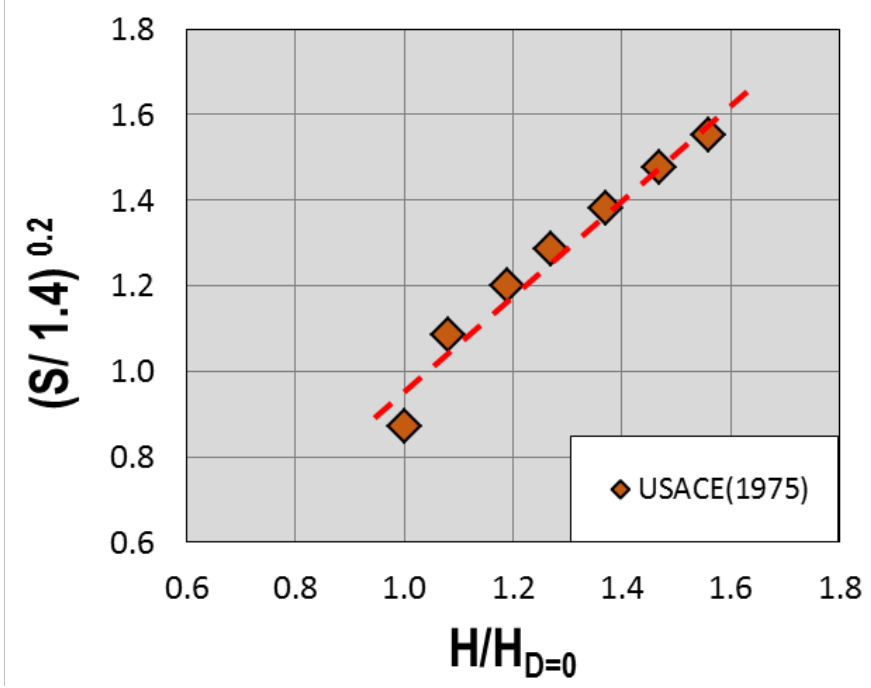

Figure 5. Linearized rock armor function data given by USACE (1975).

\section{CONCLUSIONS}

Mound breakwaters are frequently constructed in depth-limited breaking wave conditions; however, most hydraulic stability formulas given in the literature are based on small-scale tests in nonbreaking wave conditions. This study analyzes 2D physical tests of conventional two-layer rock armored breakwaters in depth-limited wave breaking conditions with a bottom slope $\mathrm{m}=2 \%$; the overtopping was zero or negligible, armor slope was $\cot \alpha=1.5$ and packing density was $\phi=1.26$. Measurements of 12 wave gauges placed along the wave flume were compared with estimations of $\mathrm{H}_{\mathrm{m} 0}, \mathrm{H}_{2 \%}$ and $\mathrm{H}_{1 / 10}$ obtained from the numerical model SwanOne. The significant wave height, $\mathrm{H}_{\mathrm{m} 0}$, measured at a distance of $3 h_{s}$ from the toe of the structure was the best characteristic wave to relate armor damage with stability number. A six-power relationship between dimensionless armor damage and stability number was found in this study; the model explained more than $94 \%$ of the variance in the damage observations.

\section{ACKNOWLEDGMENTS}

The authors acknowledge financial support from the Ministerio de Economía y Competitividad and the Fondo Europeo de Desarrollo Regional (FEDER) under grant BIA2015-70436-R. The authors thank Debra Westall for revising the paper.

\section{REFERENCES}

Battjes, J.A., and H.W. Groenendijk. 2000. Wave height distributions on shallow foreshores. Coastal Engineering, ELSEVIER, vol. 40, 161-182.

CLI. 2018. Concrete Layer Innovation. <http://www.concretelayer.com/documentation> [Accessed 5 March 2018].

Figueres, M., and J.R. Medina. 2004. Estimation of incident and reflected waves using a fully nonlinear wave model. Proc. 29th International Conference on Coastal Engineering, ASCE. World Scientific, Vol. 1, 594-603.

Gómez-Martín, M.E., Herrera, M.P., Gonzalez-Escriva, J.A., and J.R. Medina. 2018. Cubipod armor design in depth-limited wave breaking and non-overtopping conditions. Proceedings of the $7^{\text {th }}$ International Conference on the Application of Physical Modelling in Coastal and Port Engineering and Science (Coastlab18), Santander (Spain), IAHR. 
Herrera, M.P., Gómez-Martín, M.E., and J.R. Medina. 2017. Hydraulic stability of rock armors in breaking wave conditions. Coastal Engineering, ELSEVIER, vol 127, 55-67.

Iribarren, R. 1938. Una fórmula para el cálculo de los diques de escollera. M. Bermejillo-Pasajes, Madrid, Spain, (in Spanish).

Medina, J.R., Hudspeth, R.T., and C. Fassardi. 1994. Breakwater armor damage due to wave groups. J. Waterway, Port, Coastal, Ocean Eng., ASCE, 120(2), 179-198.

Melby, J.A., and N. Kobayashi. 1998. Progression and variability of damage on rubble mound breakwaters. J. Waterway, Port, Coastal, Ocean Eng., ASCE, 124(6), 286-294.

USACE. 1975. Shore Protection Manual. U.S. Army Coastal Engineering Research Center, U.S. Army Engineer Waterways Experiment Station, Vicksburg, Mississippi.

USACE. 1984. Shore Protection Manual. U.S. Army Coastal Engineering Research Center, U.S. Army Engineer Waterways Experiment Station, Vicksburg, Mississippi.

Van der Meer, J.W. 1988. Rock slopes and gravel beaches under wave attack. PhD Thesis. Technical University of Delft.

Van Gent, M.R.A., Smale, A.J., and C. Kuiper. 2003. Stability of rock slopes with shallow foreshores. Procceedings of Coastal Structures 2003, Portland, ASCE, 100-112.

Verhagen, H.J., Van Vledder, G., and S. Eslami Arab. 2008. A practical method for design of coastal structures in shallow water. Proc. 31st International Conference on Coastal Engineering, ASCE. World Scientific, Vol. 4, 2912-2922.

Xbloc. 2014. Guidelines for Xbloc Concept Designs, $<$ https://www.xbloc.com/sites/default/files/domain-671/documents/xbloc-design-guidelines-2014671-15039173271578936988.pdf> [Accessed 5 March 2018] 